\title{
Experiencia de acabamiento del pasado y pulsos vitales del sujeto. Aproximación fenomenológica al psicoanálisis de la depresión melancólica
}

\author{
JEsús GuILlermo FERRER ORTEGA \\ Bergische Universität Wuppertal \\ ferrerg@web.de
}

\begin{abstract}
Resumen: Partiendo de la fenomenología de la conciencia del tiempo, se emprende una lectura de los textos freudianos sobre Tristeza y melancolía; en concreto, se recurre a la hipótesis husserliana de un posible acabamiento del continuo retencional. Una experiencia de distanciamiento del pasado constituye la condición de renovación de los pulsos vitales; empero, inconscientemente, el melancólico no se desprende de otro sujeto, fallecido o ausente. Los síntomas del melancólico revelan un proceso paradójico, destructivo, de objetivación del otro y de devenir en objeto para el otro. Tal proceso conduce al estancamiento del flujo temporal de conciencia.
\end{abstract}

Palabras clave: fenomenología del tiempo, psicoanálisis, depresión melancólica, flujo temporal

\begin{abstract}
The author reads Sigmund Freud's text on Mourning and Melancholy on the basis of a phenomenology of time's consciousness, concretely recurring to Edmund Husserl's hypothesis on a possible cessation of the retentional continuum. A distance from the past constitutes the condition for renovation of life's pulses, but unconsciously the melancholic can't veer away from another, who has died or doesn't belong more to life's circle of the depressed subject. The symptoms of the melancholic reveal a destructive, paradoxical process of objectivating another person and becoming object for that person. This process leads to stagnancy of the consciousness temporal flow.
\end{abstract}

Key words: phenomenology of time, psychoanalytic, melancholic depression, time flow

En el marco del diálogo entre fenomenología, psiquiatría y psicoanálisis, varios autores han subrayado la importancia de describir la experiencia temporal que subyace en la depresión melancólica. Ya Ludwig Binswanger, familiarizado con la terminología husserliana, advertía que todos los casos de melancolía "degradan", por así decirlo, la evidencia meramente presuntiva (präsumptiv) de la conciencia protencional o expectativa primaria de lo venidero a una evidencia apodíctica más bien propia de la conciencia retencional o conservación de lo que ya ha sido. 
Binswanger advierte que la función normal de las protenciones consiste en abrir un horizonte de posibilidades más o menos indeterminadas, pero el sujeto melancólico prevé cualesquiera sucesos cargándolos, anormalmente, con el peso de necesidad de un pasado ya acontecido. Según Henri Maldiney, el melancólico es prisionero de un pasado que se repite indefinidamente; por consiguiente, es incapaz de contrastar la novedad de los datos presentes con expectativas del retorno de lo mismo. Marc Richir dedica análisis sumamente finos al carácter vacío de la temporalización que funda la dolencia melancólica. ${ }^{1}$

Pero, ante todo, se impone considerar el psicoanálisis de la depresión melancólica con el fin de escombrar las ambivalencias emocionales que se remontan a vivencias pasadas, así como la reiterada puesta en escena inconsciente de conflictos incesantes entre el enfermo y otro sujeto. La fenomenología de la conciencia del tiempo bien puede acompañar al psicoanálisis en la realización de su tarea, pues Husserl ha analizado no sólo vivencias donde la conciencia es transparente para sí misma, sino además modos de intencionalidad no objetivante, de paradójica presentación de lo no presente o ausente, modos incluso de presentación consciente de lo que resquebraja la coherencia de la conciencia misma. Tales modos están muy próximos al concepto freudiano de inconsciente. En este terreno de investigación cabe destacar los excelentes trabajos de Rudolf Bernet, quien ha aportado estudios de primer orden a la relación entre fenomenología husserliana y psicoanálisis freudiano. ${ }^{2}$ El presente artículo se sitúa en este cuadro de referencias y pretende continuar, con una metodología fenomenológica, líneas de trabajo ya abiertas y pertinentes para el diálogo entre filosofía y psicología.

${ }^{1}$ En este contexto de análisis fenomenológico de la depresión melancólica cabe mencionar la importancia de las siguientes obras: L. Binswanger, Ausgewählte Werke, vol. 4, Der Mensch in der Psychiatrie; H. Maldiney, Penser l'homme et la folie, y M. Richir, Phantasia, imagination, affectivité. Phénoménologie et anthropologie phénoménologique.

${ }^{2}$ Entre los numerosos textos de R. Bernet relativos a fenomenología y psicoanálisis cabe referir: "Drive: A Psychoanalytical or Metaphysical Concept? On the Philosophical Foundation of the Pleasure Principle", Philosophy Today, vol. 51 (suplementario), 2007, pp. 107-118; "Unconscious Consciousness in Husserl and Freud", Phenomenology and the Cognitive Sciences, vol. 1, no. 3, 2002, pp. 327-351; "Pulsion, plaisir et déplaisir. Essai d'une fondation philosophique des concepts psychanalytiques", Philosophie, no. 71, 2001, pp. 30-47; "L'Analyse husserlienne de l'imagination comme fondement du concept freudien d'inconscient", Alter, no. 4, 1996, pp. 43-67.

Diánoia, vol. LV, no. 64 (mayo 2010). 


\section{Presencia reiterada del pasado en la depresión melancólica (Freud)}

Al comparar la depresión melancólica con la tristeza, Freud ha logrado, al menos implícitamente, destacar los rasgos de las formas de experiencia temporal subyacentes en ambas. Ahora bien, Freud observa que los estados depresivos de índole patológica acaban contrastando con cualesquiera modos de tristeza normal. En su ensayo sobre Trauer und Melancholie, Freud indica ciertos aspectos comunes de la melancolía y la tristeza, pero también una diferencia notable: a semejanza de la tristeza, dice, la melancolía consiste en una reacción ante la pérdida de una persona, ${ }^{3}$ reacción en ambos casos acompañada por un estado de ánimo de profundo dolor, merma de la capacidad de amar, inhibición de cualquier actividad y falta de interés en el mundo exterior. No obstante, en la tristeza no se observa el rebajamiento del amor propio que una y otra vez surge en la melancolía: cuando el sujeto rememorante mira retrospectivamente el horizonte de vivencias pasadas, no halla sino motivos de autorreproche y conjetura en el vacío sobre otras posibilidades en el pasado que habrían ocasionado otro curso de acontecimientos que el vivido en el presente; cuando el sujeto mira prospectivamente el horizonte de futuro, no encuentra más que posibilidades catastróficas y espera, de manera delirante, acontecimientos de castigo.

A la autodenigración se aúna la impotencia de realizar el trabajo de duelo (Trauerarbeit), cuyo punto culminante sería la comprobación de la inexistencia, de la no presencia del objeto perdido, por así decirlo, y la reorientación de la libido hacia otros objetos. ${ }^{4}$ Así, puesto que la

${ }^{3}$ La pérdida, advierte Freud, puede concretarse como el deceso de una persona querida, pero también como la terminación de una relación amorosa, aunque la persona extrañada no haya muerto, o como la pérdida de una entidad más o menos abstracta (la patria, la libertad, un ideal, etcétera).

4 “¿En qué consiste el trabajo que efectúa la tristeza? No creo que sea forzado exponerlo de la siguiente manera: la prueba de realidad (Realitätsprüfung) ha mostrado que el objeto amado ya no existe y dicta a la libido el requerimiento de retirar todo vínculo con este objeto" (S. Freud, Trauer und Melancholie, p. 198; salvo indicación expresa, las traducciones del alemán u otros idiomas al castellano son mías). Importa sobremanera discernir los momentos del trabajo de duelo: por una parte, la resistencia (Sträuben) a desplazar la libido de la posición que había ocupado en el objeto perdido; por otra parte, la terminación de cualesquiera vínculos de la libido con el objeto perdido. ¿Pero cómo? Al parecer Freud no ha considerado más que una solución "económica", una "obra de compromiso" (Kompromißleistung) efectuada por el trabajo de duelo: la interiorización del objeto perdido; por lo tanto, un trabajo inmanente al yo, concebido por Freud como un gran depósito (Reservoir) desde el cual (a semejanza de un cuerpo protoplasmático con sus pseudópodos) se 
dolencia melancólica no logra desprenderse o tomar distancia afectiva del objeto extrañado, éste continúa psíquicamente su existencia, suscita la tendencia del sujeto a repetir compulsivamente escenas pasadas donde bullen los sentimientos ambivalentes que lo vinculaban $-\mathrm{y}$ lo vinculan aún - con el objeto perdido. Ahora bien, tales repeticiones de un escenario afectivo pasado no son conscientes. El sujeto melancólico, nota Freud, muy bien puede saber a quién ha perdido, pero no qué ha perdido en ese quién, por lo cual no hay una experiencia auténtica del pasado como tal, si por ello entendemos una experiencia de distanciamiento definitivo del objeto perdido (la imposibilidad de mencionar el qué ya perdido implica que no hay, en el fondo, un distanciamiento temporal efectivo del objeto, en el sentido de una comprobación de su inexistencia y de su carácter pretérito, ni ruptura de los lazos afectivos que tiende el objeto en su reiteración inconsciente; por consiguiente, que mientras dure el trastorno no hay posibilidad de efectuar el trabajo de duelo respecto de tal objeto). ${ }^{5}$

apresa el objeto para retornarlo al yo. No obstante, la alusión freudiana a una obra de traducción (Übersetzung) y de resignificación realizada por el duelo insinúa un ejercicio de memoria que sería a la vez conservación y distanciamiento temporal efectivo del otro, al igual que de lo otro en el sujeto mismo, ya no subsumidos en el presente de la conciencia o abarcados por él, sino indicados en su alteridad (en el sentido en que Jacques Derrida entiende la función significativa de la retención y del recuerdo). La relevancia de esta cuestión la ha subrayado en muchas ocasiones Derrida: "Si tengo éxito 'normalmente' en el proceso de introyección, entonces soy infiel al otro, el otro simplemente se vuelve parte de mí mismo, y es una forma de recordar al otro olvidándolo. El otro se vuelve parte de mí mismo y tengo una relación narcisista con el otro en mí mismo. Esto es una manera de ser, un duelo posible, pero infiel, falso, una falsa memoria del otro" (J. Derrida, Deconstruction Engaged. The Sydney Seminars, p. 66).

5 "En otros casos [...] no se puede conocer claramente lo que se ha perdido. Esta situación podría darse cuando el enfermo conoce la pérdida que ocasiona la melancolía, en la medida en que sabe quién, pero no qué ha perdido en ese quién. Ello nos sugiere referir la melancolía a una pérdida del objeto que se sustrae de la conciencia, a diferencia de la tristeza, en la cual nada de la pérdida es inconsciente" (Trauer und Melancholie, p. 199). La consecución del trabajo de duelo depende de que el sujeto entristecido venza el rechazo a cualquier acción que lo pueda apartar de la memoria constante del objeto perdido, y que, por consiguiente, traiga consigo el olvido del objeto. Cabe afirmar, pues, que la toma de conciencia de la pérdida definitiva de un objeto va a la par no sólo de la comprobación de su inexistencia, sino además de impulsos vitales que hacen saltar el marco estrecho de las asociaciones reproductivas que, haciendo del objeto echado de menos un objeto intencional, estrechan y oprimen al sujeto. Freud observa que tal distanciamiento del objeto perdido conlleva una resistencia (Sträuben), comprensible en la medida en que "el hombre no abandona gustosamente una posición de la libido", y agrega:

Diánoia, vol. LV, no. 64 (mayo 2010). 
A la pérdida del objeto se aúna la pérdida del yo, al cual el sujeto melancólico rebaja mediante los autorreproches dirigidos por cualesquiera acciones pasadas. El yo no sólo se encoge de angustia ante expectativas catastróficas, sino que se empobrece y exhibe ante los demás como un yo que ha sido, es y será moralmente condenable e indigno. Se trata, advierte Freud, de un verdadero delirio de pequeñez (Kleinheitswahn), cuyos síntomas visibles pueden ser la falta de sueño, el rechazo del alimento, pero sobre todo un estancamiento de la pulsión de conservación y continuación de la vida.

Más aún: el empobrecimiento del yo, su pérdida, arraigan en que se ha tornado objeto de una instancia de él mismo; a saber, la instancia autoritaria o superyó (Über-ich), la cual cobra vida independiente y se escinde del yo, pero que en el caso del sujeto melancólico lo hace hasta un punto extremo. Freud ha descrito así los rasgos fundamentales de esta instancia autoritaria:

Como deposición del largo período de la infancia, durante el cual el hombre en crecimiento depende de sus padres, se forma en su yo una instancia particular, en la cual se continúa el influjo parental. Tal instancia ha recibido el nombre de superyó. En la medida en que este superyó se separa del yo o se opone a éste, se vuelve una tercera fuerza ante la cual el yo debe rendir cuentas. ${ }^{6}$

Ahora bien, en la depresión melancólica, la instancia autoritaria, la institución del yo denominada "conciencia" (en el sentido de conciencia moral, Gewissen), acusa al sujeto melancólico hasta el punto de hacer que se torne en objeto, de casi reducirlo a un estado de anorganicidad y, por así decirlo, de atemporalidad o temporalización estancada, muerta. Hemos de volver sobre esta cuestión de importancia decisiva, pues se tiene razón al observar que la pulsión de muerte desempeña un papel decisivo en las patologías depresivas. ${ }^{7}$

"Esta resistencia puede ser tan intensa, que sobreviene un rechazo de la realidad y una adhesión al objeto mediante una psicosis de deseo alucinatorio" (Trauer und Melancholie, p. 198).

${ }^{6}$ S. Freud, Abriß der Psychoanalyse. Einführende Darstellungen, p. 59.

${ }^{7}$ No olvidemos las reflexiones de Freud sobre la energética psíquica y el papel que ahí desempeña no sólo el eros o pulsión amorosa (Liebestrieb), sino además la pulsión de destrucción (Destruktionstrieb), con cierto matiz sinónimo de pulsión de muerte (Todestrieb): "El fin del primero [eros] consiste en producir y conservar unidades cada vez más grandes; por lo tanto, unión. El fin de la segunda [pulsión de destrucción] consiste, por el contrario, en deshacer nexos y así destruir las cosas. A propósito de la pulsión de destrucción, podemos pensar que su último fin consiste en conducir al viviente al estado inorgánico" (Abriß der Psychoanalyse, p. 45). 
Concentrémonos ahora en la siguiente problemática: en el fondo, ¿qué culpa carga sobre sí el melancólico? Recapitulemos lo antedicho y añadamos otras consideraciones: por una parte, el psicoanálisis no contradice el testimonio del melancólico: la experiencia de culpa, como fenómeno, no es fingida, sino crudamente sincera y auténtica; ${ }^{8}$ por otra parte, como Freud recalca, "no es difícil notar que, a nuestro juicio, no hay correspondencia alguna entre la magnitud de la autodenigración y su justificación real". 9 Así —el ejemplo es de Freud-, una mujer que antes era bien educada, diligente y cumplidora se reprochará nunca haberlo sido, no hablará de sí misma mejor que otra mujer cuyos defectos saltarían a la vista.

La contradicción inherente al sufrimiento melancólico radica, por una parte, en que los autorreproches dan testimonio de una culpa auténtica en cuanto experiencia, una sensación —en cuanto tal, irrefutable o innegable - de indignidad de la propia persona; por otra parte, un rasgo esencial de tal experiencia y de esa sensación de desvaloración consiste justamente en su falta de lógica, en su oposición al juicio certero enunciado por espectadores imparciales que constatan o bien la falsedad, o bien la exageración de los autorreproches del melancólico, así como el carácter absurdo de sus fantasías catastróficas de castigo. Si consideramos lo antes dicho sobre la dimensión temporal del trabajo de duelo - en cuanto que su cumplimiento depende de la comprobación de una no existencia o no presencia, además del cese de la lucha por recordar el objeto perdido-, y si además tomamos en cuenta que la terminación del trabajo de duelo trae consigo una temporalización efectiva (la continuación de la vida abierta al futuro), entonces la contradicción de que hablamos pone al descubierto un subsuelo de vivencias pretéritas, de huellas del recuerdo que, anormalmente, no han adquirido para el sujeto melancólico el carácter de pasado (como no-más) y estancan cualquier reorientación de la libido rumbo al futuro.

Ahora bien, hay otros aspectos de la depresión melancólica que indican momentos esenciales de su estructura temporal y ayudan a aclarar

8 "Sería científica y terapéuticamente infructuoso contradecir al enfermo que alega tales cargos contra su yo. De alguna manera debe tener razón y relatar algo que sucede tal como le aparece" (Trauer und Melancholie, p. 198). En otro pasaje escribe Freud: "No resulta esencial si el melancólico tiene razón en su penoso autorrebajamiento, en la medida en que esta crítica coincidiría con el juicio de los demás. Debe tratarse más bien de que él describe correctamente su situación psicológica. Ha perdido su autoestima y debe tener buenas razones para ello. Estamos ante una contradicción [Widerspruch] que suscita un enigma difícil de solucionar" (Trauer und Melancholie, p. 201; las cursivas son mías).

${ }^{9}$ Ibid., p. 201. 
la contradicción que acabamos de exponer. El disgusto moral del melancólico, una y otra vez exteriorizado por los autorreproches, no se equipara con el de una persona normal que sufre remordimientos. Al respecto escribe Freud: "Falta la vergüenza ante los demás [...] o al menos es poco notable. Casi se podría destacar, en el melancólico, el rasgo opuesto de una urgencia de comunicación que halla satisfacción en el propio comprometimiento."10 De ahí - añade Freud- "que no se pueda evitar finalmente la impresión de que las [autoacusaciones] más fuertes con frecuencia se ajustan poco a la propia persona. Más bien, con ligeras modificaciones, atañen a otra persona que el enfermo ama, ha amado o debería amar."11

Si referimos estas reflexiones de Freud a la problemática que suscita la contradicción antes mencionada, notamos que ésta se resuelve de alguna manera. La resistencia del sujeto melancólico ante la opinión de los demás se explica, en gran medida, porque en el fondo ni su propia persona, ni su horizonte de vivencias pasadas propias están involucrados en las autoacusaciones destructivas. De ahí que fracasen cualesquiera exculpaciones provenientes de los demás, ya que el acusado públicamente es otro. Empero, el enfermo no discierne (conscientemente) quién es ese otro o, como hemos observado, quizá sabe quién es el otro cuyo deceso o cuya ausencia han originado la depresión melancólica; no sabe en cambio que los autorreproches inconscientemente tienen como objeto intencional a otro, de modo que los efectos de la intención acusadora, por así denominarla, recaen implacablemente en la propia subjetividad.

En este contexto, Freud se ha esforzado en reconstruir el proceso que ha conducido a las representaciones que el melancólico se forja de sí mismo. En el pasado, el sujeto se había decidido por un objeto fijando la libido en una determinada persona. Ahora bien, al sufrir una humillación o una decepción por parte de la persona amada, el sujeto ve cimbrada su relación con el objeto de la libido. En ese momento, el

${ }^{10}$ Trauer und Melancholie, p. 201. Empero, la "desvergüenza" o el poco pudor con que el sujeto melancólico externa su pequeñez despierta la sospecha de que sus acusaciones no inciden directamente en su yo, sino que se desvían de alguna manera, remontando a un escenario paradójicamente pretérito pero que se continúa en el ahora y se extiende al futuro. Se presiente que los autorreproches son signo dirigido hacia otro, quien es verdaderamente el objeto de las recriminaciones. Freud lo ha dicho expresamente: "Sus quejas [Klagen] son acusaciones [Anklagen], conforme al sentido antiguo de la palabra; no se avergüenzan ni se ocultan porque todo lo denigrante que enuncian en el fondo se dice de otro" (Trauer und Melancholie, p. 202).

${ }^{11}$ Ibid., p. 202.

Diánoia, vol. LV, no. 64 (mayo 2010). 
sujeto enferma debido a que no logra una solución "económica", que consistiría en apartar la libido del objeto frustrante y desplazarla hacia un objeto nuevo; más bien, la libido es retrorreferida al yo, identificado con el objeto perdido. En estas condiciones, el objeto asimilado por el sujeto pareciera no ofrecer gran resistencia ante la ocupación (Besetzung) por parte del eros. Con respecto a este proceso, escribe Freud:

Por una parte debe haber una fuerte fijación al objeto de amor [Liebesobjekt], pero por otra parte, y en contradicción con tal fijación, debe haber una resistencia mínima ante la ocupación del objeto [Objektbesetzung]. Esta contradicción parece exigir, según una acertada fórmula de O. Rank, que la elección de objeto [Objektwahl] tenga éxito sobre una base narcisista. Así en caso de que se opongan dificultades a la ocupación del objeto, ésta puede emprender la regresión al narcisismo. La identificación narcisista con el objeto será reemplazo [Ersatz] de la ocupación amorosa [Liebesbesetzung]. El éxito de tal operación consiste en que la relación con la persona amada no debe ser suprimida, a pesar del conflicto con tal persona. ${ }^{12}$

Abundemos un poco en esta última cuestión: al identificar el objeto consigo mismo, el sujeto anula las oposiciones, los rasgos no amables pertenecientes al objeto mismo. Sin embargo, surge una grave complicación:

Ahí [en el yo] no se hallaba una aplicación cualquiera [de la libido], sino servía para producir una identificación del yo con el objeto depuesto. La sombra del objeto cae sobre el yo, que ahora podía ser juzgado por una instancia particular como un objeto, como el objeto abandonado. De esta manera la pérdida del objeto se había transformado en una pérdida del yo, el conflicto entre el yo y la persona amada se había transformado en una indecisión entre la crítica del yo y el yo modificado por identificación. ${ }^{13}$

Nos encontramos aquí con otra contradicción cuyos términos opuestos, sin embargo, se muestran complementarios, pues, por una parte, la fijación al objeto frustrante es muy fuerte, hasta el punto de que el sujeto no puede romper el vínculo; y, por otra parte, el sujeto frustrado de facto rompe el vínculo con el objeto, pero realizando una maniobra peculiar que le permite conservarlo: al identificar el objeto con el yo, aquél pareciera ofrecer poca resistencia a la libido, pareciera que

${ }^{12}$ Ibid., p. 203.

${ }^{13}$ Ibid. 
su ocupación se torna, por así decirlo, más fácil. La identificación del objeto con el yo pareciera traer consigo la anulación de cualesquiera resistencias que el objeto, desde sí mismo, pudiera aún oponer al sujeto. No obstante, la maniobra de identificación fracasa y el objeto sobrevive, por así decirlo, como instancia que juzga al yo devastándolo a la vez.

Expresado de otra manera: para seguir amando a la otra persona o al objeto perdido sin tener que soportar la decepción que por sí mismos le ocasionan, el sujeto melancólico los identifica consigo mismo, procediendo así a destruir la alteridad del objeto perdido o de la persona echada de menos. No obstante este esfuerzo de aniquilación del otro objetivado, éste pervive como "aparición espectral" de sí mismo, por usar la terminología de Jacques Derrida. En efecto, el otro sujeto destruido actúa aún a título de instancia crítica que apabulla al yo melancólico, objetivándolo a su vez. Difícilmente podría concebirse una disolución más radical de un lazo intersubjetivo y un cumplimiento más terrible de las pulsiones de destrucción y de muerte, ya que dos sujetos se ven reducidos a ser objetos el uno para el otro, y paulatinamente se convierten en entidades muertas, prácticamente inorgánicas (al no haber relación propiamente intersubjetiva —más aún, al transformarse esta relación en una mutua objetivación-, se detienen los respectivos flujos de temporalización y sus pulsos vitales, se suspende la relación diacrónica como tal). Difícilmente se podría describir un proceso de operación más radical de la pulsión de muerte (Todestrieb), dirigida por el sujeto contra sí mismo, así como de las pulsiones de destrucción y apoderación (Destruktions- und Bemächtigungstriebe). Surge así una problemática que merecería un análisis más detenido: la depresión melancólica es un escenario de contrajuego entre la pulsión de muerte (nach innen) y las pulsiones de destrucción y apoderación (nach außen), donde el enfermo es el sujeto que objetiva a otro, siendo al mismo tiempo objetivado por este otro, en un proceso de mutua devastación y reducción a un estado de inorganicidad. Todo ello sin que las temporalidades respectivas logren jamás acoplarse en la coincidencia de un mismo presente (proceso destructivo que dura mientras la muerte del sujeto enfermo no acaezca o él no logre su curación).

El análisis freudiano de la melancolía se asemeja a excavaciones arqueológicas que desentierran los más remotos escenarios de disposiciones y vivencias del sujeto enfermo: para que haya por parte de la libido tanto abandono como ocupación de la persona amada, se requiere una regresión narcisista (narzißtische Regression) del sujeto; dicho con precisión: se requiere una regresión al narcisismo originario (ursprüng- 
licher Narßizmus) del sujeto; es decir, al nivel previo a la elección de objeto (Objektwahl), donde la identificación es el modo ambivalente -nos dice Freud- en que el yo designa primitivamente un objeto: "El yo quisiera incorporarse este objeto a la manera de la fase oral o caníbal del desarrollo de la libido, a la manera del devorar [Fressen]."14

Así pues, en los casos de depresión melancólica el sujeto se ve retrorreferido a un estadio temprano de la vida (Urzustand des Lebens), donde la ambivalencia emocional de amor y odio respecto del objeto muestra matices peculiares, "primitivos" en el sentido propio de la palabra. El sufrimiento del melancólico se ve agravado porque, la mayor parte de las veces, las ocasiones de regresión al narcisismo originario desbordan el fallecimiento de una persona querida: cualesquiera situaciones de humillación, desatención o decepción, dentro del marco de cualquier índole de relación o trato intersubjetivo, arrastran al sujeto melancólico hacia una situación de narcisismo originario previa a la elección de objeto y a una efectiva temporalización intersubjetiva.

Hemos subrayado que, por obra de la regresión narcisista, el sujeto logra, con cierta facilidad, fijar su eros en el objeto identificándolo con el yo. Tal identificación aligera, en un principio, el proceso de ocupación del objeto por la libido, pues, por una parte, el impulso espontáneo de ésta se dirige hacia el sujeto mismo y, por otra, el sujeto emprende una retirada, al menos provisional, ante los aspectos frustrantes del objeto. Asimismo, se eluden cualesquiera resistencias que un objeto nuevo pudiera ofrecer a la libido. Empero, en el momento de la regresión narcisista, el yo se escinde gravemente: por un lado, sigue siendo el sujeto de las emociones ambivalentes que aún lo vinculan con el objeto; por otro, debido a la identificación del objeto con el yo, el sujeto mismo se torna objeto de tales sentimientos alternantes: el sujeto melancólico no puede claudicar de su amor al objeto, pero al mismo tiempo necesita abandonarlo, de ahí que la libido huya hacia la identificación narcisista; ahora bien, una vez efectuada la regresión, el sujeto cobra venganza de sí mismo en calidad de reemplazo (Ersatzobjekt), odiándose insulta, humilla y hace sufrir al objeto, y así obtiene una satisfacción sádica. "La ocupación amorosa del objeto por parte del melancólico ha experimentado un doble destino: por una parte ha regresado a la identificación, pero por otra, bajo el influjo del conflicto de ambivalencia, ha sido colocada en el nivel del sadismo."15

${ }^{14}$ Ibid.

${ }^{15}$ Ibid., p. 205.

Diánoia, vol. LV, no. 64 (mayo 2010). 
El tema del sadismo inherente a los autorreproches del enfermo muestra tener una gran relevancia para la comprensión de la experiencia temporal propia de la melancolía. Hemos aludido antes al regreso del sujeto melancólico a un estado originario de la vida, previo a la elección de objeto, un estado donde impera el narcisismo, pero como amor propio del yo, como motor de la angustia ante cualesquiera amenazas. Sin embargo, la regresión narcisista que efectúa el melancólico conlleva una autodestrucción tal que cabe preguntarse cómo la orientación de la libido a la autoconservación (Selbsterhaltung) se convierte en un impulso de muerte (es marcada la tendencia al suicidio en la depresión melancólica). La respuesta de Freud es sumamente ilustrativa: "El análisis de la melancolía nos enseña que el yo sólo puede matarse cuando, mediante el retorno de la ocupación del objeto, se trata a sí mismo como objeto y puede dirigir contra sí la animosidad a un objeto, animosidad que representa la reacción originaria del yo contra objetos del mundo exterior."16

Freud describe así una situación peculiar del sujeto melancólico, en cuyo inconsciente ${ }^{17}$ se escenifica reiteradamente una relación ambivalente y destructiva con un objeto que se resiste a pasar, a nunca más ser presente, que cobra vida como instancia crítica y aplasta al yo hasta la depresión y la inhibición extremas. ${ }^{18}$ Ello radica en que el melancólico se muestra incapaz de cumplir la tarea propia del duelo, que consiste en aceptar el veredicto de la realidad sobre cualesquiera re-

${ }^{16} \mathrm{Ibid}$., p. 206.

${ }^{17}$ Desde el punto de vista tópico, como observa Freud, sólo cabe situar el conflicto de ambivalencia emocional que padece el melancólico en el sistema $U b w$ (Unbewusstes, inconsciente), el cual es ámbito de las huellas del recuerdo (Erinnerungsspuren). Hay que tomar en cuenta que la ambivalencia emocional respecto del objeto, o bien remonta a una disposición subjetiva, constitucional, que afecta cualesquiera de sus relaciones amorosas, o bien remonta a vivencias traumáticas que surgen ante la amenaza de pérdida del objeto.

${ }^{18}$ Debido al carácter restringido de este trabajo no nos podemos ocupar de los estados de manía, en los cuales se puede convertir fácilmente la depresión melancólica. Baste ahora indicar que, según Freud, melancolía y manía "luchan" (ringen) contra el mismo complejo (Komplex). La manía es un aparente vencimiento del objeto que, mediante su presencia reiterada, sojuzga al sujeto en estado de depresión melancólica. La euforia del maníaco y su disposición a cualesquiera actividades parecieran triunfar sobre el objeto, dejándolo atrás definitivamente; empero, se trata únicamente de la voracidad de un yo que permanece hambriento y empobrecido por la persistencia del complejo, por más que quiera saciar su libido con nuevas ocupaciones de objetos. Del horizonte futuro del maníaco jamás está excluido un nuevo episodio de depresión melancólica; por el contrario, ésta es una amenaza siempre en ciernes. 
cuerdos y expectativas en relación con el objeto que ya no existe más. Desde el punto de vista tópico, cabe decir que tal veredicto de la realidad (experiencia del pasado como algo que ya no existe más) se torna operante (en el caso de la tristeza normal) cuando las huellas del recuerdo (Erinnerungsspuren) que mantienen en vida el conflicto con el objeto (la lucha entre odio y amor, aquél por retirar la libido del objeto, éste por conservarla fija en el objeto) pasan, sin obstáculo, del sistema Ubw (Unbewusstes, inconsciente) al sistema Vbw (Vorbewusstes, preconsciente).

Ahora bien, tal tránsito implicaría que el sujeto puede tomar conciencia de contenidos inconscientes reprimidos (verdrängt) y así tornarlos inoperantes, dándoles el carácter o sentido de no-más-presentes. La tristeza normal, nos dice Freud, logra que el yo renuncie al objeto, que lo declare "muerto" (tot) y concede al yo el "premio de permanecer en vida" (die Prämie des Amlebenbleibens). La consecuencia inmediata de tal logro es la posibilidad de acabamiento del proceso autodestructivo que tiene lugar en el inconsciente. El sujeto melancólico, mientras no sea curado, carece de tal posibilidad. El conflicto sin fin que acaece en el inconsciente se asemeja a una herida abierta (offene Wunde) que consume todas las energías del sujeto para terminar desangrándolo. (Aquí conviene tener en cuenta una observación que se nos podría hacer con justa razón: el tránsito del material inconsciente a la conciencia no es suficiente para la superación de un conflicto psíquico. Freud mismo ha advertido, en muchas ocasiones, que el momento patógeno no es el no saber, Nichtwissen, sino la fundación del no saber en resistencias internas, innere Widerstände, que causan y sostienen el no saber. La toma de conciencia de la causa de la dolencia psíquica tampoco es factor de una curación; de ser así, le bastaría al paciente leer libros de psicología para recuperar su salud psíquica. Por eso Freud insiste en el llamado proceso de reelaboración para salir al paso de la compulsión de repetición, Wiederholungszwang.)

Estas reflexiones sobre el análisis freudiano de la melancolía suscitan una pregunta que nos remite a los análisis fenomenológicos de la autoconstitución de la subjetividad: ¿no se insinúa la objetivación inconsciente de sí misma, discernible en la experiencia melancólica, como una especie de "proceso de descomposición" de la subjetividad, en tanto que ésta es originariamente conciencia no objetivante del flujo de vivencias e impulsos vitales, tal como la describe Edmund Husserl? Formulemos esta interrogante de otra manera: ¿por qué la regresión narcisista trae como consecuencia un proceso de autoobjetivación destructiva y estancamiento de la subjetividad, siendo ésta originariamente 
tanto autoconciencia no objetiva como autotemporalización fluyente? ${ }^{19}$ Justamente esta cuestión, me parece, subyace en la problemática de una falla del recuerdo normal, que de otro modo culminaría en una experiencia de distanciamiento del pasado, de comprobación de la ausencia definitiva del objeto perdido (por consiguiente, culminaría en la posibilidad de significar el objeto perdido en su ausencia, en la posibilidad de una memoria del otro echado de menos, la cual no sería interiorización o identificación narcisista). ${ }^{20}$

${ }^{19}$ Me parece oportuno citar aquí unos pasajes del magnífico libro de Bernhard Waldenfels, Bruchlinien der Erfahrung, que nos sugieren ideas interesantes sobre la experiencia temporal subyacente a la depresión melancólica. Al referirse al fenómeno de una autodestrucción del sujeto, escribe Waldenfels lo siguiente: “¿Qué puede significar la autodestrucción de la vida, que ofrezca resistencia a sí misma? Sólo puede significar que la vida no está en unión consigo misma, que es invadida por algo ajeno [dass es von einem Fremden heimgesucht wird] que aparece en la perturbación, antes [bevor] de que se manifieste como algo perturbador, ajeno, hostil, odiado y por destruir" (B. Waldenfels, Bruchlinien der Erfahrung. Phänomenologie. Pychoanalyse. Phänomenotechnik, p. 358). En el caso de la experiencia melancólica, el objeto, mediante su prosecución psíquica, invade al yo que se identifica con él, sin perder por eso su carácter de algo ajeno al yo (por eso adquiere la forma de una instancia crítica); el objeto se adelanta siempre, por así decirlo, a cualquier manifestación suya en la conciencia que lo distanciaría temporalmente dándole el carácter de pasado, de no-más-presente.

${ }^{20}$ Aquí conviene hacer dos observaciones importantes: a) A mi modo de ver, Husserl no separa tajantemente originariedad y normalidad, autoconciencia originaria y autoconciencia normal, como si las estructuras trascendentales de la conciencia del tiempo interior se pudieran describir aparte, por así decirlo, valiendo indistintamente para la constitución de experiencias que, sólo a posteriori, serían o bien normales o bien posiblemente anómalas. Aquí se impone una lectura a fondo de los textos donde Husserl nos habla sobre la constitución del mundo a partir de la normalidad, donde la facticidad de las anomalías se describe como posibilidad $a$ priori de un sujeto en el mundo, ello en la medida en que originariedad equivale a una normalidad expuesta al exterior. Debido a la necesidad de restringir nuestro trabajo, no podemos abordar en detalle tales textos. Baste ahora con hacer referencia al nuevo volumen de la serie Husserliana, donde se hallan reflexiones de importancia decisiva para elaborar una fenomenología de la anormalidad: E. Husserl, Die Lebenswelt. Auslegungen der vorgegebenen Welt und ihrer Konstitution. Texte aus dem Nachlass (1916-1937), Husserliana, vol. 39; cfr. en particular las pp. 215-225; 314-318; 637-661. b) Ciertamente, Husserl ha insistido en que la rememoración (Wiedererinnerung) puede reanimar el continuo de retenciones oscurecidas e incluso vacías, presentando así otra vez una experiencia pasada. Idealmente, observa Husserl, es concebible una rememoración adecuada de una vivencia anterior. Empero, no se ha subrayado lo suficiente, en mi opinión, otros textos donde Husserl describe el progreso pasivo de la rememoración, las generalidades, oscuridades y oscilaciones inherentes a las presentificaciones (Vergegenwärtigungen) propias del 
Importa sobremanera señalar que no se trata, en principio, de una falla que se traduce en representaciones ilusorias del pasado como presente, aunque la fijación de la libido en el objeto pueda desembocar en fantasías neuróticas y alucinaciones. ${ }^{21} \mathrm{La}$ experiencia patológica de un presente reiterado del objeto, de su no acabamiento, se concreta como un desdoblamiento inconsciente del yo, por el cual el objeto, en su prosecución psíquica, adquiere la forma de una instancia autoritaria que objetiva al yo mismo y amenaza aniquilarlo. Mi propósito en los siguientes apartados consistirá en relacionar esta problemática de una presencia destructiva del pasado en la experiencia melancólica, con los análisis fenomenológicos de Edmund Husserl sobre la extinción (Abklang) retencional y los pulsos vitales del flujo de conciencia.

\section{Experiencia de terminación del continuo retencional e impulsos vitales nuevos (Husserl)}

Husserl ha distinguido tajantemente entre la constitución de objetividades temporales individuales (sean inmanentes o trascendentes) y la autoconstitución del flujo de la conciencia (Bewusstseinsfluss) o "subjetividad absoluta". Los objetos temporales duran (dauern) extendiéndose como unidades idénticas en el tiempo, transcurren como procesos (Vorgänge) que admiten una mayor o menor velocidad respecto de la duración que cumplen en el tiempo. En cambio, las fases del flujo de conciencia cambian permanentemente, no son unidades idénticas que se prolonguen en el tiempo; por lo tanto, no son duraciones ni procesos, sino las maneras de donación (Gegebenheitsweisen) de los objetos en la conciencia, maneras que siguen un ritmo constante de modificación

recuerdo, la interrupción de un impulso a la resurrección del pasado, interrupción que parece ser constitutiva de la experiencia del pasado como tal, de lo ya-nopresente. Ya me he ocupado de esta problemática en una ponencia titulada "Sufrimiento melancólico y conciencia del tiempo", la cual será incluida en la publicación de las Actas del Coloquio Internacional Edmund Husserl: Perspectivas actuales de la fenomenología. En memoria del 70 aniversario de muerte, editadas por la UACM (en prensa). He ahondado en estas cuestiones en otro trabajo, donde emprendí un ensayo de análisis fenomenológico del recuerdo, la conciencia de imagen y de fantasía, recurriendo al estudio de Freud sobre un caso de depresión melancólica; a saber, la historia del pintor Christoph Haizmann. Cfr. G. Ferrer, "Fantasía, recuerdo y depresión melancólica. Aproximación fenomenológica a un caso analizado por Sigmund Freud", La lámpara de Diógenes, vol. 10, 2009, pp. 65-88.

${ }^{21}$ Las fantasías neuróticas presentifican (vergegenwärtigen) el objeto perdido "como si" estuviera presente, mientras que las alucinaciones, como Husserl ha mostrado, no se diferencian estructuralmente de las percepciones. 
continua. Para comprender esta distinción situémonos en el nivel de la constitución temporal de un objeto inmanente, de una sensación por ejemplo, o mejor aún, de una constelación de sensaciones (en concreto, no se da en el campo de conciencia una sensación aislada, sino una multiplicidad de sensaciones originarias que se desvanecen según un ritmo constante): hallamos entonces la donación de un grupo de sensaciones a la manera del "llegando de una vez" (auf einmal kommend), a la del "siendo ahora de una vez" (auf einmal jetzt seiend) y a la del "yéndose de una vez" (auf einmal weggehend). El paso de una manera de donación a las otras es constante, continuo, sin interrupción. ${ }^{22}$ En este contexto de descripción fenomenológica del flujo, la denominada conciencia protencional presentaría el grupo de sensaciones en su arribo, arribo inminente, abarcándolas bajo la forma del "llegan de una vez"; la conciencia impresional presentaría inmediatamente el grupo de sensaciones, abarcándolas bajo la forma del "son ahora de una vez", y la conciencia retencional presentaría el grupo de sensaciones bajo la forma del "se van de una vez". 23

Importa sobremanera notar que Husserl no aísla protención, impresión y retención. Estas designaciones conciernen a momentos esenciales de la constitución de cualesquiera objetividades temporales, pues la conciencia de un dato de sensación, para atenernos a nuestro ejemplo, requiere que se le identifique sintetizando los puntos de su duración que están por venir, que son ahora o que apenas han transcurrido. Ahora bien, Husserl insiste en que la conciencia misma del flujo de maneras de donación no exige una conciencia anterior que sintetice

22 "Varias, muchas protosensaciones (Urempfindungen) son 'a la vez', y cuando una fluye, la multiplicidad fluye a la vez, enteramente del mismo modo, con el mismo tempo [...]" (E. Husserl, Zur Phänomenologie des inneren Zeitbewusstseins (1893-1917), p. 77.

${ }^{23}$ Teniendo en mente nuestra problemática general, he subrayado las palabras "presentaría" y "forma" para resaltar provisionalmente la aparente oposición entre "presentación" y "presentificación" (Vergegenwärtigung), "intuición" y "signo" de una parte, entre "estructura" y "génesis" de otra parte. Un filósofo de la talla de Jacques Derrida, uno de los primeros en reparar en la tensión que suscitan aquellas distinciones, no las considera sino para descubrir otras posibilidades de desarrollo inherentes a la fenomenología misma que las establecidas dogmáticamente. Husserl mismo no describe la intuición propia de la protención y de la retención sin mencionar que se trata de una peculiar intuición de lo no presente; Husserl mismo no describe la forma del presente viviente como abarcante de cualesquiera fases del flujo, por distantes que parezcan, sin mencionar que de facto experimentamos discontinuidades del flujo. Tendremos ocasión de volver sobre estas cuestiones de suma importancia e indicar su relevancia para el tema de la experiencia melancólica. 
las fases sucediéndose las unas a las otras. La multiplicidad de fases del flujo no debe comprenderse como una multiplicidad de apariciones por sintetizar y referir a un polo objetivo idéntico, sino como una multiplicidad dada de una vez, en presente, a la conciencia. Dicho de otro modo: el flujo de las maneras de donación se caracteriza de entrada como autoconciencia, como percepción no objetivante de sí mismo (Sich selbst-Wahrnehmung), como tener conciencia de sí mismo en el presente viviente, sin que discontinuidades o diferencias temporales hagan presuponer una conciencia constituyente de la temporalidad peculiar del flujo, que a su vez postularía otra conciencia y así in infinitum.

Ciertamente Husserl describe el flujo como autoconciencia de alguna manera temporal (puesto que sus fases se suceden unas a otras sin interrupción alguna, aunque la designación pretemporal, vorzeitlich, conviene mejor al flujo). No obstante, al preguntarse cómo se autoconstituye la temporalidad fenomenológica (phänomenologische Zeitlichkeit) de la subjetividad, en cuanto que ésta es una corriente (Strom) de las maneras de dación de los objetos, Husserl se ve obligado a confrontar una y otra vez el problema de un posible regressus in infinitum, tal como lo hemos expuesto en las líneas anteriores. Se estaría tentado de solucionar esta dificultad describiendo el flujo de conciencia, el presente viviente (lebendige Gegenwart), como una "forma", como un "mecanismo formal" de extensión del presente: la conciencia protencional presentaría de una vez todo lo que está por venir del dato de sensación, mientras que la conciencia retencional presentaría de una vez todo lo que está por irse del dato de sensación. Al ser dadas de una vez las fases del flujo en el presente de la autoconciencia, no habría, presuntamente, discontinuidades en el flujo que harían temer la necesidad de una ulterior conciencia que deba sintetizar "pausas" o "síncopas" del ritmo de la corriente de maneras de donación.

Ahora bien, no nos parece que una interpretación de la conciencia del tiempo interior como un mecanismo formal de autoconciencia presente a sí misma se apoye firmemente en los textos de Husserl. Al menos en la medida en que Husserl, a propósito de la conciencia del flujo, jamás omite de la descripción fenomenológica las autoexperiencias no objetivantes de discontinuidad (pausas, arribo de lo nuevo inesperado o de lo parcialmente distinto de lo esperado), de transición de la irrealidad en realidad (del futuro en el presente), de la realidad en irrealidad (del presente en el pasado), de autodistanciamiento temporal, etc. ${ }^{24}$ Para fines de nuestro trabajo, importa destacar los análisis donde Husserl

${ }^{24}$ En este apartado nos basamos principalmente en el texto número 4 de los Manuscritos de Bernau: Die Bernauer Manuskripte über das Zeitbewusstsein (1917-

Diánoia, vol. LV, no. 64 (mayo 2010). 
considera la posibilidad de una experiencia de acabamiento del continuo de retenciones (Aufhören des retentionalen Kontinuums), la cual equivaldría a una autoconciencia no objetivante de distanciamiento temporal de sí mismo, en la cual se constituiría la experiencia de distanciamiento irreversible del pasado objetivo. Incluso ha comprendido Husserl esta posibilidad de clausura del pasado como posible fundamento de la renovación constante de pulsos vitales (Lebenspulsen), de apertura a lo nuevo que afecta al sujeto. Una vez que hemos llegado a este punto, cabe formular así la hipótesis que guiará nuestras reflexiones: la regresión narcisista, el proceso inconsciente de autoobjetivación destructiva, mortífera incluso, que emprende el melancólico consistiría en la actualización de una posibilidad a priori de inversión o involución de la vida trascendental, cuyos pulsos de vida sólo se renuevan a partir del acabamiento de la prosecución psíquica de una presencia que, de continuar en la conciencia, amenazaría con impedir la apertura a lo nuevo, por consiguiente, a la existencia misma.

Vayamos al problema que nos atañe: sin duda Husserl ha querido mostrar que la retención, no obstante ser conciencia no objetivante de una fase transcurrida del flujo, pertenece al campo de presencia (Präsenzfeld). No en vano caracteriza Husserl la retención como una pospresentación (Postpräsentation) de la impresión originaria (Urimpression). A diferencia de la rememoración, la retención ase (hält) lo ya-

1918), pp. 65-84. Al leer los escritos de Husserl sobre la estructura fundamental de la conciencia del tiempo (Grundstruktur des Zeitbewusstseins), impresiona hondamente cómo surgen oposiciones, tensiones, que sugieren la posibilidad de una dialéctica interior en la descripción de los fenómenos. Husserl afirma, por ejemplo, que "el presente es conciencia omniabarcante; por así decirlo, omnisciente de sí misma y de sus consistencias [intentionale Bestände]. La estructura del presente implica, como posibilidad ideal, omnisciencia del mundo [...]" (Hua XXXIII, 45). Empero, en otro pasaje - por citar uno entre muchos en el mismo tenor- nos dice Husserl: "Conciencia no es sólo presente o realidad [Wirklichkeit]. La conciencia era y será, y como conciencia presente en su realidad es a la vez conciencia de una corriente de conciencia pasada, así como de una corriente de conciencia futura arribando" (Hua XXXIII, 45, 21-25). No nos parece que para ser fiel a la descripción fenomenológica haya que resolver las oposiciones prefiriendo una alternativa en vez de otra; más bien hay que mostrar cómo los momentos de tensión dialéctica son constitutivos de los fenómenos mismos. Ya Eugen Fink había observado que los análisis fenomenológicos (como Husserl los efectúa con una precisión y profundidad sin parangón) se abren espontáneamente al complemento de la dialéctica: "La dialéctica no debe oponerse a la manera fenomenológica de pensar, como si fuera ajena, otro método de pensar. Más bien se trata de suscitar la inquietud dialéctica del pensamiento a partir de las ideas fenomenológicas" E. Fink, Nähe und Distanz. Phänomenologische Vorträge und Aufsätze, p. 245. 
no-presente y lo conserva en el presente viviente (lebendige Gegenwart). Así pues, la retención carece de cualesquiera rasgos de una reproducción rememorativa, que no es tal sino distanciada del objeto que no se deja asir por el acto presente de recuerdo. Ahora bien, si es verdad que el acento recae sobre la copertenencia del ahora y sus modificaciones retencionales en el presente viviente, Husserl se topa, sin embargo, con el fenómeno paradójico de un paulatino apagamiento, desvanecimiento o una extinción (Abklang) ${ }^{25}$ del continuo retencional.

La dificultad que conlleva esta noción no resquebrajaría, al parecer, la primacía del presente, pues no obstante el inevitable hundimiento del continuo retencional en la oscuridad, a pesar de la pérdida en diferencias intuitivas, aquél siempre se dejaría medir como una gradualidad en el ritmo de vaciamiento (Entleerung) respecto del punto 0 de la modificación (Nullpunkt der Modifikation), de la abundancia intuitiva sin más: el ahora impresional (impressionales Jetzt) ${ }^{26}$ Dicho de otra manera: la forma modal del presente abarca cualesquiera momentos del continuo retencional, incluso aquellos cuyo contenido intuitivo se ha vaciado por completo. Ello se debe a que, por obra de una aprehensión retencional, el presente viviente se extiende a todos los puntos del continuo retencional (los ya vacíos también) sucediéndose con un ritmo ininterrumpido: nos referimos a la creciente imbricación retencional de los contenidos

${ }^{25}$ Se verá que, en última instancia, no resulta posible decidirse por una u otra traducción del término Abklang, pues, por una parte, las palabras "apagamiento" y "desvanecimiento" sugieren la idea de una oscuridad potencialmente iluminable (por la rememoración) y, por lo tanto, de una latencia de lo retenido; por otra parte, la palabra "extinción" sugiere la idea de un término o acabamiento del continuo retencional. Ahora bien, tanto tendencia a la recuperación como distanciamiento definitivo constituyen nuestra experiencia concreta del pasado.

26 "El apagamiento [das Abklingen] es un empobrecimiento constante, un adelgazamiento [Abnahme] constante de la abundancia [Fülle], según la cual hablamos de intuitibilidad [Anschaulichkeit] y sus grados; por lo tanto, un adelgazamiento de la intuitibilidad con límite cero [Grenze Null], en el cual ya no se puede hablar más de intuitibilidad" (Hua XXXIII, 66, 21-26). En su magnífico libro La Vie du sujet. Recherches sur l'interprétation de Husserl dans la phénoménologie, Rudolf Bernet ha puesto de relieve las paradojas que trae consigo una descripción fenomenológica de la conciencia retencional, que es asunto de "retención de objetos immanentes sucesivos, pero también retención de la sucesión de los objetos, y retención de la forma de esta retención" (R. Bernet, La Vie du sujet, p. 232). No obstante, ya el solo concepto de conciencia retencional (por la cual es captada posterior y originariamente una fase del flujo de conciencia) sugiere la idea de una presencia de la conciencia que "se hace sobre un fondo de ausencia, la conciencia no se da sino en tanto que ha sido dada como [habiendo sido dada como (habiendo sido dada como...)]" (Ibid., p. 235). 
hiléticos transcurridos; a saber, retención de retención, retención de retención de retención, retención de retención de retención de retención, y así indefinidamente. ${ }^{27}$

Tratemos de precisar la problemática que nos sugieren los textos de Husserl: por un lado, el vaciamiento de los contenidos retenidos sugiere prima facie una experiencia (no objetivante) de acabamiento de la continuidad del presente; ${ }^{28}$ por lo tanto, sugiere un autodistanciamiento temporal originario, una conciencia originaria de sí mismo como ausente. Por otro lado, Husserl nos habla de una especie de "medición", desde el ahora, del apagamiento retencional, aunque los contenidos retenidos aparezcan como extintos en el flujo de conciencia. Quizá cabría asemejar la conciencia del continuo retencional así descrita a un oído capaz de escuchar siempre la constancia de un ritmo y su redoblamiento, en última instancia, las "resonancias de la propia voz", por mucho que el volumen de los contenidos de retención haya disminui-

${ }^{27} \mathrm{Al}$ comentar el texto número 4 de los Manuscritos de Bernau, Marc Richir formula con exactitud el problema que nos ocupa: "En el fondo se trata siempre de un acuerdo entre la continuidad de variación de la aprehensión intencional y la continuidad decreciente de los desvanecimientos, que supuestamente constituyen la hyle (impresional) de la primera" (M. Richir, Phantasia, imagination, affectivité. Phénoménologie et anthropologie phénoménologique, p. 469). En esta misma obra - cuya relevancia para la fenomenología contemporánea no podría exagerarse-, Richir emprende un análisis sumamente fino de la problemática de los fenómenos de apagamiento. Cfr. sobre todo las pp. 468-481.

${ }^{28}$ En un trabajo notable sobre la fenomenología husserliana del tiempo, Alexander Schnell ha advertido un cambio de orientación en los Manuscritos de Bernau respecto de las Lecciones: en aquéllos Husserl ya no caracteriza la fase originaria del flujo de conciencia como impresión, sino como núcleo incluido en la intencionalidad (intentional beschlossener Kern), punto de saturación del momento de proximidad [cumplimiento intuitivo de una protención]. Los fenómenos de apagamiento o extinción (Schnell traduce Abklang como "évanouissement", sinónimo de la palabra castellana "desvanecimiento") son una paradójica disminución del carácter de núcleo (Kernhaftigkeit) de la fase originaria, paradójica porque la disminución progresiva equivale al progreso e incremento de la modificación (retención de retención, retención de retención de retención, etc., a pesar del vaciamiento de los contenidos retenidos). No obstante, como advierte Schnell, Husserl no se obstina en describir los fenómenos de Abklang como presentes, sin consideración alguna de la "despresentación" (Entgegenwärtigung) que operan, como Eugen Fink ha querido mostrar. Al respecto escribe Schnell: "Husserl, quien no dispone de tal concepto, se ve obligado a dar cuenta de la manera como este 'presente' desvanecido es dado, y sabe muy bien que este modo de donación se distingue del propio de las impresiones actuales reales (reelle)" (A. Schnell, Temps et phénomène. La phénoménologie husserlienne du temps (1893-1918), p. 209).

Diánoia, vol. LV, no. 64 (mayo 2010). 
do y vaya aún a disminuir más. ${ }^{29}$ La conciencia asiría en el presente viviente cada punto del continuo de retenciones, incluso uno vacío de contenido intuitivo, ya no visualizándolo (resulta en última instancia imposible mirar lo vacío), sino por así decirlo escuchándolo seguir el ritmo de una modificación in crescendo (retención de retención, retención de retención de retención, etcétera). ${ }^{30}$

Así se explica la paradoja de que Husserl caracterice la conciencia retencional como tendencia negativa al vaciamiento (negative Tendenz zur Entleerung) e incremento (Steigerung) a la vez; en este contexto podríamos decir que se trata de un incremento de presencia del sujeto en el no-más-presente de cada modificación retencional, aunque ésta conduzca la presencia a la oscuridad y al vacío. En función de nuestra temática, conservemos aquí la idea de una autoconciencia cuyo presente se extiende mediante la escucha de sí mismo, aun en la mayor lejanía concebible. Ahora bien, ¿no arraiga en tal manera de extensión y continuidad del presente la posibilidad de que la voz del sujeto, por usar una terminología de Jacques Derrida, se vuelva contra el escucha mismo, por ejemplo, como instancia autoritaria que destruye al yo, como sucede en el caso de la regresión narcisista del sujeto melancólico? Lo cierto es que Husserl atiende y concede relevancia al tema de cierta posibilidad ideal, que ya no sería la posibilidad de prolongación indefinida de un presente autoconservándose en su apagamiento, y a pesar de él: tanto en los trechos de apagamiento de contenidos concretos, como en los trechos de apagamiento considerados en cuanto forma abstracta, se impone una restricción (Beschränkung),

${ }^{29}$ Desde luego, nos valemos de estas metáforas pensando en las reflexiones de Jacques Derrida en su obra clásica La Voix et le phénomène, donde escribe: "La voz se escucha. Los signos fónicos [...] son escuchados por el sujeto que los profiere en la proximidad absoluta de su presente" (J. Derrida, La Voix et le phénomène. Introduction au problème du signe dans la phénoménologie de Husserl, p. 85).

${ }^{30}$ Debo indicar las imperfecciones y ambivalencias de la metáfora que he utilizado: si hablamos de una continuidad del flujo retencional que "se escucha" a pesar de la distancia, no nos referimos a la audición de contenidos que tarde o temprano se tornarán inaudibles, como sería el caso de un tono retenido que finalmente no escuchamos más, sino de una paradójica audición del ritmo con que se incrementa constantemente lo asido retencionalmente, con que se extiende la forma del presente, por mucho que su contenido haya empobrecido hasta tornarse "inaudible": retención de retención, retención de retención de retención, etc. En última instancia, he recurrido a una imagen insuficiente para expresar el asimiento continuo de contenidos de retención, por mucho que se hayan vaciado completamente. 
que se expresa en dos aspectos de las modificaciones de apagamiento: según una idealización matemática, las modificaciones van hasta el infinito; empero, en lo finito (im Endlichen) tienen un límite (Limes). Ello significa que idealmente se puede concebir una modificación que no experimenta una modificación ulterior. ¿Pero cómo es posible que tal modificación tenga un presente y, por lo tanto, deba apagarse? De ninguna manera es fácil responder a esta pregunta. (Hua XXXIII, 66, 9-21)

Al leer cuidadosamente este texto salta a la vista la idea de una paradójica modificación retencional de la protoimpresión o protopresencia que consistiría en la experiencia del cese de la modificación de apagamiento, en un desasimiento del presente. Husserl se desconcierta un tanto y nota la dificultad para describir fenomenológicamente esta experiencia, pues ella apunta a una autoconciencia, al nivel del flujo, equivalente a una captación (no objetivante) de la distancia temporal definitiva de sí mismo respecto de un presente anterior acabado; más que de una captación del cese de la modificación de apagamiento, cabría hablar de ya no escuchar (ni asir más), en la distancia, el ritmo constantemente redoblado de la modificación retencional de contenidos incluso oscuros y vacíos.

Una vez que la modificación de apagamiento concluyera (por obra de una modificación retencional paradójica —o "retencional" de otra manera- equiparable al cese de cualquier modificación de apagamiento ulterior), la experiencia pasiva del no-más-presente ya no se mediría según la gradualidad del incremento negativo de la protoimpresión por obra de la modificación retencional (decimos incremento negativo, porque la Steigerung de la modificación retencional —retención de retención, retención de retención de retención, etc.- consiste en un progresivo vaciamiento de los contenidos retenidos hasta la oscuridad total). Se trataría de una paradójica conciencia retencional que en vez de ser intuición (Anschauung) de un diminuendo constante del presente, sería quizá signo (Anzeichen) o presentificación (Vergegenwärtigung) del acabamiento de un continuo de retenciones, del cese de su pertenencia al campo de presencia.

Por ende, no habría más asimiento (Halten) de contenidos retenidos vacíos en el presente del flujo, sino conciencia de una interrupción brusca del ritmo constante con que se incrementaba el continuo retencional. La forma del ahora (Jetztform) ya no se extendería a ulteriores puntos del continuo retencional, porque éste se habría acabado sin más. Importa sobremanera subrayar que tal modificación paradójica del continuo retencional, por la cual se experimentaría el término de ulteriores modificaciones, no equivaldría a la negación absoluta de una conciencia 
posterior de lo acabado, sino a una experiencia de lo terminado como tal, de lo no-más-presente en cuanto se ha sustraído del "puño retencional" (retentionaler Griff). Quizá la conciencia de un término de la modificación de apagamiento indefinido iría a la par de la conciencia de una distancia temporal irreversible entre la fuerza afectiva (affizierende Kraft) de la protopresencia nueva ${ }^{31}$ y lo definitivamente concluido, ya no-más-presente. El ahora impresional sería medida del después rete-

${ }^{31} \mathrm{Al}$ ocuparse de las relaciones complejas entre la protoimpresión y la espontaneidad de la conciencia, Husserl advertía que ni la retención ni la protención —figuras de la espontaneidad de la conciencia - crean la hyle (materia) o dato de sensación presente, tan sólo lo modifican. La protoimpresión "viene de afuera" (kommt von außen her), por lo tanto no se reduce a ser un simple resultado de la síntesis de la conciencia del tiempo, sino más bien inaugura, mediante su arribo "desde el exterior", la producción (Erzeugung) de los continuos de modificación retencional y protencional. Léanse los siguientes pasajes de las Lecciones sobre fenomenología de la conciencia interna del tiempo: "La protoimpresión es el comienzo absoluto de esta producción, la fuente originaria a partir de la cual se produce todo lo demás. Empero, la protoimpresión misma no es producida, no surge como algo producido, sino por genesis spontanea; ella misma es producción originaria (Urzeugung). No crece (no tiene germen), es creación originaria (Urschöpfung)" (Hua X, 100, 28-33). En seguida Husserl añade que cada impresión "es lo producido originariamente (das Urgezeugte), lo 'nuevo', lo que ha devenido de manera ajena a la conciencia (das bewusstseinsfremd Gewordene), lo recibido (das Empfangene) a diferencia de lo producido por la espontaneidad de la conciencia. La peculiaridad de esta espontaneidad consiste en que sólo desarrolla e incrementa lo producido originariamente, pero no crea algo 'nuevo'" (Hua X, 100, 39-44). Una "hilética" de la conciencia tendría que describir y aclarar la genesis spontanea, el arribo de la protoimpresión con su carácter de novedad. Me parece acertada en gran medida la definición de tal hilética que, comentando los textos citados, propone László Tengelyi: "a esta hilética corresponde dar cuenta de la emergencia de la novedad que se forma, como Husserl ha dicho justamente, de manera extraña a la conciencia" (L. Tengelyi, "L'Impression originaire et le remplissement des protentions chez Husserl", p. 34). En su contribución a este volumen colectivo, Tengelyi advierte que la caracterización de la protoimpresión como dato nuevo y sustraído a la producción de la espontaneidad de la conciencia pareciera chocar con la definición del presente como "cumplimiento de una protención", definición que Husserl introduce en los Manuscritos de Bernau. No podemos seguir aquí los matices que Tengelyi indica en los Manuscritos y en otros textos, haciendo comprender que, en el fondo, el carácter de irrupción de la protoimpresión no se niega ni se ve disminuido. En lo que concierne a este artículo, digamos tan sólo que la fuerza afectiva de la protoimpresión nueva adquiere mayor relieve contrastando con el continuo retencional que se va apagando, más aún si éste llega a término definitivamente. El acabamiento de un continuo retencional aliviaría la conciencia protencional, por así decirlo, al concluir la espera de una repetición de lo mismo, tanto en su arribo como en su hundirse en el pasado. 
nido, por así decirlo, ya no abarcándolo bajo la gradualidad rítmica de incremento negativo de la modificación retencional, sino contrastando, por su fuerza afectiva, con un no-más-presente clausurado definitivamente.

Debemos reconocer que Husserl vacila al considerar esta hipótesis del acabamiento del continuo de apagamiento, e insiste en que no conviene debilitar la idea de síntesis de identificación de un mismo contenido fluyente, síntesis operada por la conciencia impresional y la conciencia retencional, pues tal síntesis fundamenta la constitución de una duración objetiva gracias a la rememoración de una experiencia pasada. ${ }^{32}$ No obstante, desde otra perspectiva la idea de un cese del continuo de apagamiento cobra, para Husserl, una notable relevancia: en la gradualidad del incremento de la modificación retencional (que se extiende indefinidamente como en línea recta, por así decirlo) Husserl discierne una contratendencia encaminada al punto cero de la intensidad (das intensitätsartiges Null), donde acabaría el fenómeno de apagamiento continuo. La paradójica modificación de la modificación retencional de que hemos hablado - mejor dicho aún: la presentificación de una experiencia pasiva de la terminación del apagamiento, en suma, del final abrupto del incremento o extensión de un trecho retencional del presente viviente- constituiría, junto con la tendencia a la continuidad, un rasgo esencial de la vivacidad de la conciencia (Bewusstseinslebendigkeit). Al respecto escribe Husserl:

Conciencia es vida, y toda vida, en sus pulsos vitales particulares [besondere Lebenspulse], es vivir en el pasar [Verleben], en el ir de la vida hacia un término [Dahingehen des Lebens], y toda vida concreta de la corriente vital es una unidad de pulsos vitales siempre nuevos, que por su parte "surgen" [auftreten] y "transcurren" [vergehen], se desvanecen [dahinschwinden]. (Hua XXXIII, 69, 19-23)

La renovación de los pulsos vitales del sujeto exige el vaciamiento progresivo, si no la extinción completa, de la presencia retencional de contenidos por cuya aprehensión (Auffassung) un objeto o un acontecimiento son susceptibles de rememoración. Quizá cabría aseverar

32 "Si queremos evitar todo lo que no nos procura la identificación de toda una corriente [Abfluss] como donación pasiva, debemos decir: a través de todas las fases tenemos un contenido como sentido y abundancia." Husserl añade enseguida que, a pesar del adelgazamiento de la abundancia, el sentido de un contenido de retención, por ejemplo el color negro, permanece igual e idéntico (Hua XXXIII, 69, $1-8)$. 
que la presentificación de un punto cero de intuitibilidad constituye la plataforma, la perspectiva de una reorientación de la vida trascendental hacia posibilidades que ya no procura el asimiento de contenidos vacíos o en vías de terminación. Ahora bien, ¿qué resulta de estas reflexiones si las aplicamos al análisis freudiano de la depresión melancólica?

Ante todo, reporta ganancias la sola posibilidad de aplicar una terminología propiamente fenomenológica a la situación del sujeto enfermo. Salta a la vista que el melancólico padece una merma significativa de sus pulsos vitales: la vivacidad de la autoconciencia del flujo (inconsciente de alguna manera, en tanto no objetivante, prerreflexiva) consiste en la reanudación de los pulsos vitales a partir de la presentificación o de la aparición de un punto cero de la intuitibilidad decreciente del continuo retencional. Cabe designar la renovación de los pulsos vitales como una contratendencia que sale al paso de la inevitable terminación de intuitibilidad de los contenidos de retención.

La modificación protencional que se abre a lo nuevo constituye justamente una inversión del movimiento retencional en dirección al vacío. Empero, pareciera que en el caso del sujeto melancólico, lejos de que los pulsos vitales se orienten hacia afecciones nuevas, se encaminan en dirección opuesta, hacia la conservación indefinida de los contenidos de retención, por cuya aprehensión objetivante el sujeto escenifica una y otra vez el conflicto con la persona extrañada (si no mediante la rememoración voluntaria y explícita, porque ciertos contenidos han sido reprimidos, sí mediante la conciencia de imagen, en cuyas relaciones con el inconsciente freudiano habría que ahondar).

Ahora bien, no se trata sólo de que la situación del sujeto melancólico pueda esclarecerse mediante el uso de un vocabulario y de conceptos fenomenológicos. Por su parte, el psicoanálisis plantea cuestiones que obligan a la fenomenología trascendental, si no a contradecir sus principios fundamentales, sí a explorar posibilidades de descripción e incluso de especulación dialéctica (como ha sugerido Fink) que desbordan los marcos impuestos por interpretaciones dogmáticas o literales. Si consideramos los análisis de Freud sobre la regresión narcisista efectuada por el melancólico, entonces se insinúa la idea de que tanto en la detención de los pulsos vitales del enfermo, como en la fijación patológica en el tiempo vacío del continuo retencional, subyace una energética destructiva y paradójicamente entrópica, la cual amenaza radicalmente ya no sólo una reorientación hacia lo nuevo, sino el carácter presuntamente omniabarcante de la forma del presente viviente, la posibilidad (presupuesta constantemente por Husserl) de que retenciones incluso vacías "pospresenten", "mantengan asido" o "conserven" el ahora im- 
presional. A esta posibilidad se opone una contraposibilidad de la cual da testimonio el drama de la depresión melancólica: un estancamiento y cese de los pulsos vitales del flujo de conciencia a fuerza de mantener asido un presente que se continúa en los fenómenos de apagamiento. Podría caracterizarse esta contraposibilidad de manera más terrible: mientras la regresión narcisista se sustraiga a la autoconciencia reflexiva, los pulsos vitales del sujeto melancólico se detendrán poco a poco, irán a contrapelo de la tendencia protencional a la plenitud intuitiva, se encaminarán hacia un estado prácticamente de hundimiento en el vacío y finalmente anorganicidad. Todo ello ocurre en un escenario inconsciente, donde otro, al tiempo que es objetivado, objetiva al sujeto mismo "tetanizando" - por usar una expresión de Marc Richir — la vida trascendental originaria.*

\section{BIBLIOGRAFÍA}

Bernet, R., La Vie du sujet. Recherches sur l'interprétation de Husserl dans la phénoménologie, Presses Universitaires de France, París, 1994.

Binswanger, L., Ausgewählte Werke, vol. 4, Der Mensch in der Psychiatrie, ed. A. Holzhey-Kunz, Roland Asanger Verlag, Heidelberg, 1995.

Derrida, J., Deconstruction Engaged. The Sydney Seminars, ed. P. Patton y T. Smith, Power Publications, Sydney, 2009.

__ La Voix et le phénomène. Introduction au problème du signe dans la phénoménologie de Husserl, Presses Universitaires de France, París, 1967. [Versión en castellano: La voz y el fenómeno, trad. P. Peñalver, Pre-textos, Valencia, 1981.]

Fink, E., Nähe und Distanz. Phänomenologische Vorträge und Aufsätze, Karl Alber, Friburgo/Munich, 2004.

*Con este artículo pretendo continuar la investigación comenzada con mi ponencia "Sufrimiento melancólico y conciencia del tiempo", presentada durante el Coloquio Internacional Husserl (México, abril de 2008). La problemática que ahora desarrollo surgió en gran medida en el contexto del diálogo y discusión que, muy amablemente, el doctor Antonio Zirión Quijano ha sostenido conmigo a propósito del mencionado escrito. Asimismo, agradezco al doctor László Tengelyi el brindarme la oportunidad de impartir una conferencia sobre este tema titulada "Zur Problematik des Verhältnisses von Protention und Urimpression im Lichte der melancholischen Erfahrung", en el marco de las organizaciones del Institut für phänomenologische Forschung der Bergischen Universität Wuppertal (cfr. G. Ferrer, "Zur Problematik der Zeiterfahrung der melancholischen Depressivität im Lichte der Husserschen Phänomenologie", Revista Internacional de Fenomenología y Hermenéutica ALEA, no. 7, 2009, pp. 131-160). Por último, agradezco las valoraciones críticas de quienes consideraron pertinente la publicación de este texto en la revista Diánoia. 
Freud, S., Trauer und Melancholie, en Freud-Studienausgabe, vol. 3, Psychologie des Unbewussten, S. Fischer, Fráncfort del Meno, 1975.

, Abriß der Psychoanalyse. Einführende Darstellungen, introd. F.W. Eickhoff, Fischer Taschenbuch, Fráncfort del Meno, 2009 (1a. ed.: Sigmund Freud Werke im Taschenbuch, ed. Ilse Grubrich-Simitis, 1994).

Husserl, E., Die Bernauer Manuskripte über das Zeitbewusstsein (1917-1918), Husserliana, vol. 33, ed. R. Bernet y D. Lohmar, Kluwer Academic Publishers, Dordrecht/Boston/Londres, 2001.

- Die Lebenswelt. Auslegungen der vorgegebenen Welt und ihrer Konstitution. Texte aus dem Nachlass (1916-1937), Husserliana, vol. 39, ed. R. Sowa, Springer, Dordrecht, 2008.

_ Z Zur Phänomenologie des inneren Zeitbewusstseins (1893-1917), Husserliana, vol. 10, ed. R. Boehm, Martinus Nijhoff, La Haya, 1966.

Maldiney, H., Penser l'homme et la folie, Éditions Jérôme Millon, Grenoble, 2007.

Richir, M., Phantasia, imagination, affectivité. Phénoménologie et anthropologie phénoménologique, Éditions Jérôme Millon, Grenoble, 2004.

Schnell, A., Temps et phénomène. La phénoménologie husserlienne du temps (1893-1918), Georg Olms, Hildesheim, 2004.

Tengelyi, L., "L'Impression originaire et le remplissement des protentions chez Husserl", en J. Benoist (comp.), La Conscience du temps. Autour des Leçons sur le temps de Husserl, Vrin, París, 2008.

Waldenfels, B., Bruchlinien der Erfahrung. Phänomenologie. Psychoanalyse. Phänomenotechnik, Suhrkamp, Fráncfort del Meno, 2002.

Recibido el 6 de mayo de 2009; aceptado el 14 de octubre de 2009. 